\title{
Region-specific enhancers near two mammalian homeo box genes define adjacent rostrocaudal domains in the central nervous system
}

\author{
Christopher K. Tuggle, ${ }^{1,4}$ Jozsef Zakany, ${ }^{1,2}$ Luciano Cianetti, ${ }^{3}$ Cesare Peschle, ${ }^{3}$ and \\ M. Chi Nguyen-Huu ${ }^{1,4}$ \\ ${ }^{1}$ Departments of Microbiology and Urology, Columbia University, New York, New York 10032 USA; ${ }^{2}$ Institute of Genetics \\ of the Hungarian Academy of Sciences, 6701 Szeged, Hungary; ${ }^{3}$ Department of Hematology-Oncology, Istituto Superiore di \\ Sanita, I-00161 Rome, Italy.
}

To gain insight to the mechanisms underlying region-specific gene expression in mammalian development, we investigated the regulatory DNA associated with the proximal promoter of two homeo box genes, murine $H o x-$ 1.3 and human Hox-5.1. Using $\operatorname{lacZ}$ gene fusions in transgenic mice, we identified regulatory elements in the $5^{\prime}$-flanking sequences of the Hox-1.3 and the Hox-5.1 genes that specifically direct $\beta$-galactosidase expression to the brachial and the upper cervical regions (respectively) of the central nervous system (CNS). These two elements act at the transcriptional level, are active in either orientation, and confer region-specific expression to unrelated promoters, satisfying the criteria for enhancer elements. The two spatial domains defined by these enhancers are directly adjoining, extend along the rostrocaudal axis for the same span of 6-7 metameres, and represent specific subsets of the overall CNS regions expressing all endogenous Hox-1.3 or Hox-5.1 transcripts. The adjacent domains in the developing murine CNS that express Hox-1.3 and Hox-5.1 gene fusions are strikingly reminiscent of the adjacent stripes of expression in Drosophila embryos seen with Sex combs reduced and Deformed, the two Drosophila homeotic genes most homologous to Hox-1.3 and Hox-5.1, respectively. These findings represent the first demonstration of region-specific mammalian enhancers and raise the possibility that the mammalian CNS may be subdivided into a series of rostrocaudal domains on the basis of the activity of enhancers near homeo box genes.

[Key Words: region-specific gene expression; homeo box genes Hox-1.3 and Hox-5.1; mammalian CNS]

Received September 18, 1989; revised version accepted November 21, 1989.

The homeo box, a 180-bp DNA segment that encodes a protein domain with specific DNA binding properties, has been found in several Drosophila genes implicated in the control of development (McGinnis et al. 1984a; Scott and Weiner 1984; for review, see Gehring 1987). Products of these genes may activate or repress transcription of specific target genes during embryogenesis (Hiromi and Gehring 1987; Jaynes and O'Farrell 1988). Vertebrate homeo box-containing genes have also been identified and isolated (Carrasco et al. 1984; McGinnis et al. 1984b; McGinnis et al. 1984c; for review of murine genes, see Fienberg et al. 1987) and have been found to be specific DNA-binding proteins (Fainsod et al. 1986; Odenwald et al. 1989) as well as regulators of transcription (Mangalam et al. 1989). A role for these genes in mammalian developmental processes has not yet been defined; however, ectopic expression of Hox-1.1 in cra-

${ }^{4}$ Present address: Department of Microbiology, University of Southern California, Los Angeles, California 90033 USA. niofacial structures (Balling et al. 1989) or overexpression of Hox-1.4 in the colon (Wolgemuth et al. 1989) produces developmental abnormalities in transgenic mice. Evidence of homeotic transformation, namely the alteration of regionally identifiable structures (as exhibited by Drosophila homeotic mutants), was not observed. Therefore, it is still uncertain whether the mammalian homeo box-containing genes are functional homologs to those in Drosophila. The expression of mammalian homeo box genes of the Antennapedia class (Hox genes) in specific rostrocaudal regions of the neuroectoderm and mesoderm, however, indicates that these genes may play an important role in the specification of the body plan (Holland and Hogan 1988). This hypothesis is significantly reinforced by the observation that, in striking similarity to the situation in Drosophila, Hox genes are also organized in clusters, and the order of the genes in the clusters corresponds to the order of their anterior limits of expression along the anterior-posterior axis (Boncinelli et al. 1988; Gaunt et al. 
1988; Graham et al. 1989; Duboule and Dolle 1989; Giampaolo et al. 1989; for review, see Akam 1989; Wright et al. 1989).

Very little is known currently about the cis-acting regulatory elements controlling region-specific expression in embryogenesis. Recently, the analysis of several Drosophila homeotic and segmentation genes in transgenic flies has begun to define the regulatory elements responsible for the specific pattern of expression seen in these genes. In the fushi tarazu (ftz) gene, for example, an upstream element located within a 2600-bp fragment has been shown to direct expression of a heterologous promoter in a striped pattern, mimicking that of $f t z$, and to be active in either orientation (Hiromi and Gehring 1987). Thus the regulatory element(s) in ftz have characteristics of an enhancer active only in specific regions of the developing embryo.

We began an analysis of the spatial regulation of Hox genes during murine embryogenesis because knowledge of region-specific regulatory elements is extremely limited in mammals and because understanding the mechanisms of spatial gene expression may also shed light on the processes underlying morphogenesis and pattern formation. Initially, we analyzed the spatial and temporal expression of murine Hox-1.3 gene fusions in transgenic mouse embryos (Zakany et al. 1988). These studies defined a 912-bp regulatory region of Hox-1.3 that directs the expression of a lacZ reporter gene to the brachial region of the spinal cord, that is, to the CNS region between the fourth cervical (C4) and second thoracic (T2) metameres (Zakany et al. 1988). This pattern was striking in its high degree of specificity at the anterior and posterior limits; no expression of $\beta$-galactosidase was observed in metamere $\mathrm{C} 3$ or more anterior metameres, and similarly no expression was observed in T3 or more posterior metameres. Being limited to a discrete rostrocaudal region, the $\beta$-galactosidase pattern is reminiscent of the expression pattern of homeotic genes in Drosophila embryos and is similar to the spatial distribution of the $\mathrm{X} 1 \mathrm{H}$ boxl homeo box proteins in Xenopus and murine embryos (Oliver et al. 1988; Wright et al. 1989). On the other hand, the $\beta$-galactosidase pattern clearly does not recapitulate the entire expression pattern of the Hox-1.3 gene as determined by in situ RNA analysis, where expression at midgestation is observed in the hindbrain and the entire spinal cord, as well as in several mesodermal derivatives such as prevertebrate, metanephros, lungs, and stomach (Dony and Gruss 1987). The finding that DNA flanking a homeo box gene can direct expression to only a subset of endogenous expression sites has also been observed with Drosophila homeo box gene fusions /Goto et al. 1989; Harding et al. 1989) and could have biological or artifactual causes. For example, because the 912 -bp fragment contains only one of the two Hox-1.3 promoters previously identified (designated proximal and distal, Odenwald et al. 1987; Zakany et al. 1988; Fibi et al. 1988; Murphy et al. 1988; Garbern et al. 1989), it is possible that the two promoters have different spatial expression patterns, and that the observed $\beta$-galactosidase pattern specifically re- flects the spatial expression of the proximal promoter located within the 912-bp fragment. In this context, we note that the reported in situ RNA pattern (Dony and Gruss 1987) was obtained with a common probe that detected both proximal and distal transcripts. Alternatively, the $\beta$-galactosidase pattern may accurately reflect the Hox -1.3 proximal protein pattern, which may differ from the proximal Hox-1.3 RNA pattern as a result of translational control mechanisms. This latter situation is possible because transgene also contains Hox-1.3 5 '-untranslated mRNA sequences which could contribute to translational control. Finally, it is also possible that the expression pattern observed in the brachial spinal cord is artifactually created as a result of the interruption of Hox-1.3 control sequences by the insertion of $l a c Z$ sequences.

We conducted experiments that argue against the role of translational control or artificially created regulatory elements and that demonstrate the importance of transcriptional control in the observed spatial expression of Hox-1.3/lacZ genes. We extended our analysis to the human homeo box gene Hox-5.1 (Mavilio et al. 1986; Featherstone et al. 1988) and showed that the regulatory mechanisms and the spatial and temporal expression patterns found with Hox-1.3 are not unique but can be observed with another homeo box gene. Here, we report our analysis of the spatial and temporal expression of Hox-1.3 and Hox-5.1 gene fusions in transgenic mice. Interestingly, this analysis has led to the identification of two region-specific enhancers near these genes and to the definition of two adjacent rostrocaudal domains in the developing CNS.

\section{Results}

Hox-1.3 regulatory elements are separable into a proximal promoter element and an orientationindependent element(s) required for region-specific expression in the embryonic spinal cord

A 912-bp DNA fragment located immediately $5^{\prime}$ to the Hox-1.3 protein-coding region fused to the lac $Z$ gene (construct B/1.3/lacZ in Fig. 1) was sufficient to direct $\beta$-galactosidase expression to dorsal cells in the brachial region of the embryonic spinal cord, that is the region between the fourth cervical (C4) and second thoracic (T2) metameres (Zakany et al. 1988). However, a lacZ fusion with only the $3^{\prime} 308 \mathrm{bp}$ of this DNA fragment, which contains the proximal Hox-1.3 promoter and 5'untranslated mRNA sequences (termed fragment $C_{\text {; }}$ construct 1.3 /lacZ in Fig. 1), was inactive, indicating that the deleted 604-bp fragment (termed fragment $B$ ) is necessary for region-specific expression. Because the only promoter elements in the 912-bp fragment have been mapped to fragment C (Murphy et al. 1988; Zakany et al. 1988; Garbern et al. 1989), it follows that no promoter elements and only regulatory elements are present on fragment $B$. To determine if these regulatory elements have the enhancer property of functioning in either direction, and to demonstrate that the $\beta$-galacto- 
Tuggle et al.

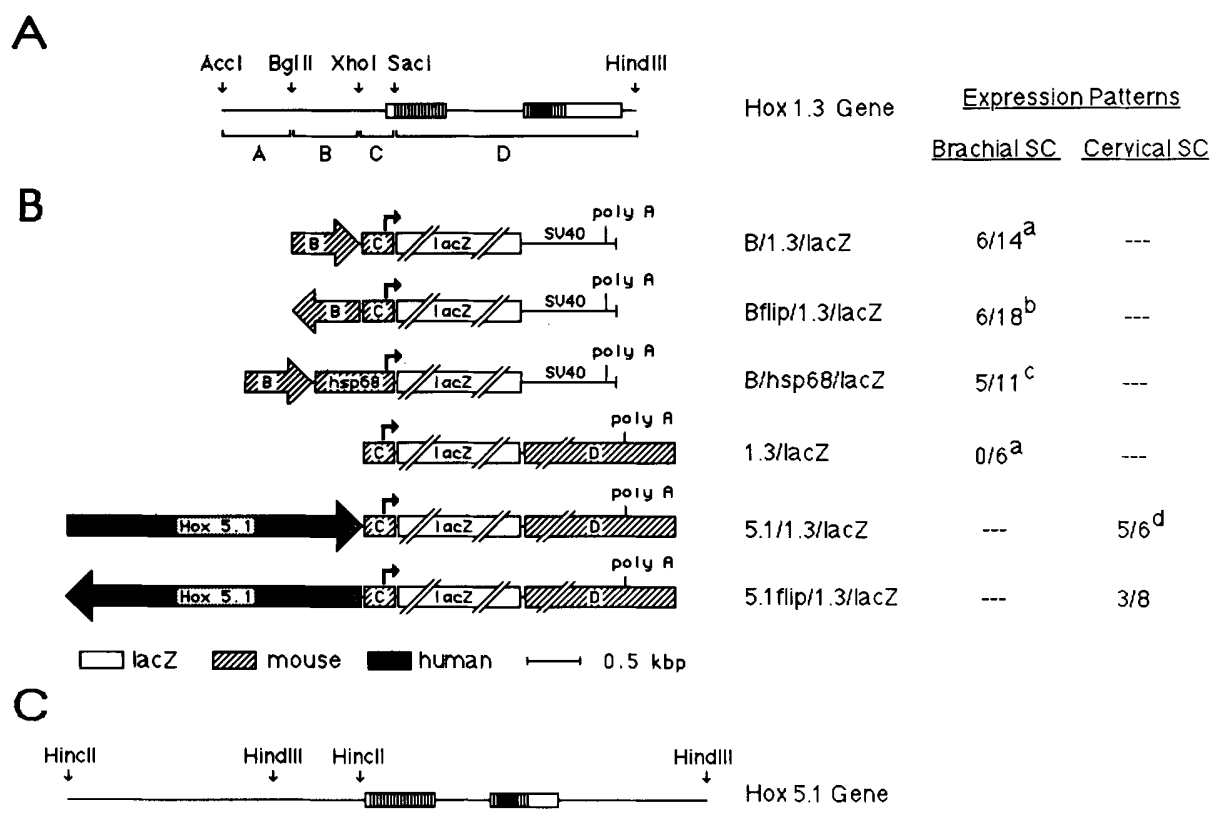

Figure 1. Structure and expression of homeo box fusion genes in transgenic mice. (A) Structure of the Hox-1.3 genomic region and proximal transcript. Exons are shown in boxes, translated region in close parallel lines, and the homeobox in black. $(B)$ Structure and expression of transgenes. All schematic representations are to scale except for the $1 a c Z$ gene and fragment D. DNA fragments B and Hox-5.1, which contain enhancer elements, are depicted as large arrows, whereas other DNA fragments are depicted as boxes. Small arrows above fragment $C$ indicate start of transcription from the Hox-1.3 proximal promoter. Expression is listed as the number of expressing embryos (lines) over the total number of transgenic mice obtained per construct. a Data from Zakany et al. 1988. bFloorplate

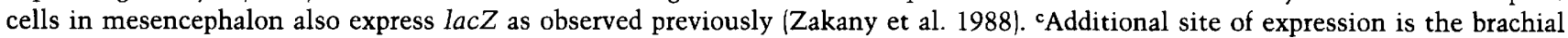
peripheral nervous system, which was observed in three embryos (data not shown). Two of five expressors are $F_{0}$ embryos, the other three of five are expressing transgenic lines. $(C)$ Structure of the human Hox-5.1 genomic region. Symbols used are as in $A$.

sidase activity observed was indeed attributable to the initiation of transcription only within fragment $\mathrm{C}$, we reversed the normal orientation of fragment $B$ with respect to fragment $\mathrm{C}$. This fusion gene (Bflip/1.3/lac Z in Fig. 1) was injected into one-cell embryos, and trans-

Figure 2. In situ detection of $\beta$-galactosidase activity in Bflip/ $1.3 /$ lacZ and $\mathrm{B} /$ hsp68/lacZ transgenic embryos. (A) Wholemount lateral view of day 12.5 embryo showing expression of Bflip/1.3/lacZ gene fusion in the brachial spinal cord region. $(B)$ Dorsal view of embryo in $A$ showing two columns of expressing cells. $(C)$ Histological cross section of embryo in $A$ shows $\beta$-galactosidase activity is observed only in the dorsal region of the spinal cord. (Magnification, 20×.) (D) Whole-mount lateral view of day 12.5 embryo expressing $\mathrm{B} / \mathrm{hsp} 68 /$ lacZ gene fusion in the brachial region of the spinal cord. There is also a low level of expression in the sacral region of the spinal cord. $(E)$ Dorsal view of embryo in $D$, showing mosaic expression of $\beta$ galactosidase within the brachial region. $\langle F\rangle$ Histological cross section of embryo in $D$ shows expression of $\beta$-galactosidase is in the dorsolateral cells of the spinal cord exclusively. (Magnification, $20 \times$.) Line in $A$ and $D$ is drawn to show plane of section in $C$ and $F$, respectively. (SC) spinal cord. genic embryos were generated and analyzed for $\beta$-galactosidase activity. Of the eighteen transgenic embryos obtained, six expressed this gene fusion. Figure 2, A-C shows whole mounts and a cross section of a representative day 12.5 embryo expressing Bflip/1.3/lacZ. Strong
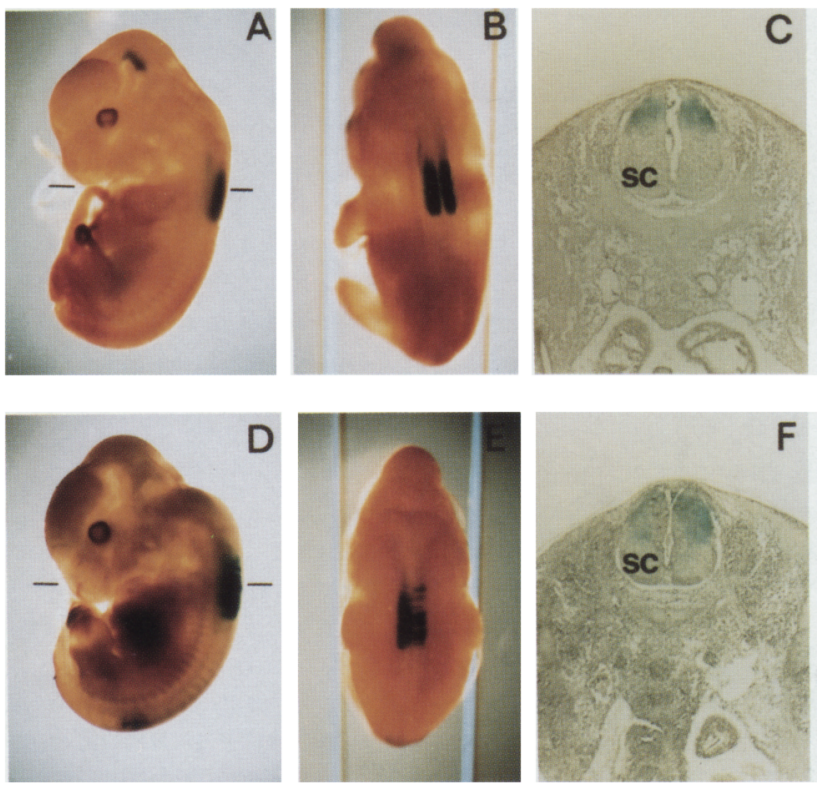
$\beta$-galactosidase activity can be observed in the dorsal cells of the brachial spinal cord, as well as in the mesencephalon floorplate cells. This expression pattern is identical to that observed for the $\mathrm{B} / 1.3 / 1 a c Z$ construct (Zakany et al. 1988) and indicates that regulatory elements within fragment $B$ act in an orientation-independent manner. This result argues that fragment $B$ contains enhancer-like elements that act in conjunction with fragment $\mathrm{C}$ to produce the region-specific pattern observed. However, this result does not define whether region specificity is mediated by the enhancer elements within fragment $B$; by the promoter elements, potential regulatory elements (Odenwald et al. 1989), the 5'-untranslated mRNA sequences on fragment $C$, or by a combination thereof. The next experiment was undertaken to address this issue.

Region-specific expression in the CNS of Hox-1.3/lacZ transgenic mice is controlled at the transcriptional level by an enhancer(s) located within a 604-bp fragment

The Hox-1.3 protein, when synthesized in the baculovirus system, binds at least one specific site within fragment C (Odenwald et al. 1989). This indicates that fragment $\mathrm{C}$, in conjunction with $H o x-1.3$ protein, may be important in the regulation of the Hox-1.3 gene. Therefore, it was of interest to determine whether fragment $\mathrm{C}$, while insufficient, is necessary for expression in the brachial spinal cord, or whether fragment B, while necessary, is also sufficient for the expression pattern observed. To determine whether region specificity can be directed by fragment $B$ only, we replaced fragment $C$ in $B / 1.3 / 1 a c Z$ gene with the promoter and $5^{\prime}$-untranslated sequences from the mouse $h s p 68$ gene. These hsp 68 sequences, when fused to the lacZ gene, are silent in mouse embryos in the absence of stress or nearby regulatory elements (Kothary et al. 1988); therefore, any $\beta$-galactosidase activity in transgenic embryos carrying the $\mathrm{B} / \mathrm{hsp} 68 /$ lacZ gene should be attributable to regulatory elements on fragment B. Fragment B was placed upstream of the hsp68-lacZ fusion (construct $\mathrm{B} / \mathrm{hsp} 68$ / lac $Z$ in Fig. 1), and transgenic mice were generated and analyzed as above. Of the eleven transgenic embryos obtained, five showed $\beta$-galactosidase activity at day 12.5 of gestation. Expression of the transgene in a representative embryo can be observed in the dorsolateral cells of the brachial spinal cord (Fig. 2D-F), mimicking the results observed when the Hox-1.3 promoter is regulated by the $\mathrm{B}$ fragment enhancer (constructs $\mathrm{B} / 1.3 / 1 \mathrm{acZ}$ and Bflip/1.3/lacZ). This result indicated that 1) the Hox -1.3 promoter and 5 '-untranslated sequences on fragment $C$ are dispensable, 2) the region-specific expression of $1 a c Z$ is produced at the transcriptional level as no Hox-1.3 $5^{\prime}$ untranslated sequences are present in the hsp/lacZ RNA encoding $\beta$-galactosidase, and 3) the enhancer elements on fragment $B$ are sufficient to confer region-specific expression onto an unrelated $h s p 68$ promoter. With the $\mathrm{B} /$ hsp68/lacZ fusion gene, expression was not observed in the mesencephalon, an ectopic site observed in $\mathrm{B} / 1.3$ /
lacZ embryos. There is also a low level of $\beta$-galactosidase expression in the sacral region of the spinal cord. However, expression in this region was observed in only two $\mathrm{B} / \mathrm{hsp} 68 / \mathrm{lacZ}$ embryos out of five expressors and was observed occasionally in other Hox-1.3-lacZ transgenic mice (C.K. Tuggle, J. Zakany, and M.C. NguyenHuu, unpubl.), thus it is difficult to judge the significance of expression in this region.

Regulatory sequences near human Hox-5.1 direct lacZ expression to the upper cervical CNS of transgenic mice

To explore how general is the phenomenon of regionspecific enhancers operating near homeo box genes, we searched for regulatory elements near other homeo box genes. The homeo box gene Hox-5.1 is located in a different complex, Hox-5. Like Hox-1.3, Hox-5.1 is expressed at the RNA level in the murine embryonic CNS, but the rostral boundaries of expression of the two genes are different (Featherstone et al. 1988; Gaunt et al. 1988). The transcription pattern of both Hox-1.3 and Hox-5.1 is characterized by multiple mRNAs derived from more than one promoter (Mavilio et al. 1986; Zakany et al. 1988; Graham et al. 1989; L. Cianetti and C. Peschle, unpubl.). We considered the possibility that sequences near the Hox-5.1 proximal promoter (i.e., the one proximal to the initiation codon) may function in an analogous manner to the identified enhancer region at the Hox-1.3 proximal promoter. Therefore we fused a 2832-bp HincII fragment located just $5^{\prime}$ to the proximal promoter (L. Cianetti and C. Peschle, unpubl.) and protein-coding region of the human Hox-5.1 gene (previously called c13, Mavilio 1986) upstream of the 1.3/ $1 a c Z$ fusion gene, which has been shown to be inactive in midgestational embryos (Zakany et al. 1988, construct $1.3 /$ lacZ in Fig. 1). This gene fusion (construct 5.1/1.3/lacZ in Fig. 1) was used to generate both transgenic embryos (which were analyzed 12 days after DNA microinjection) and transgenic mouse lines for analysis of transgene expression during gestation. Figure 3 shows whole mounts and a cross section of a representative embryo carrying this $5.1 / 1.3 / 1 a c Z$ fusion gene. Similar to $\mathrm{B} / 1.3 / \mathrm{lacZ}$, the $5.1 / 1.3 / \mathrm{lacZ}$ fusion gene shows tissuespecific expression in dorsolateral cells of the spinal cord. However, the interesting difference is that expression of $5.1 / 1.3 / 1 a c Z$ is found in the upper cervical region of the spinal cord (from the caudal myelencephalon to metamere C3) rather than in the brachial region (from metamere C4 to metamere T2). Expression in this upper cervical region was observed in five out of six independent transgenic embryos and lines (see table in Fig. 1), and must be attributable to the presence of Hox-5.1 regulatory elements on the transgene. As has been already observed with $\mathrm{Hox}_{-1.3 / 1 a c Z}$ gene fusions, expression of $H o x-5.1 / 1.3 / 1 a c Z$ in the upper cervical spinal cord does not recapitulate the entire Hox-5.1 RNA expression pattern as determined by in situ hybridization analysis; using probes that detect all forms of Hox-5.1 mRNA, expression has been detected in the myelencephalon, throughout the spinal cord and in several prevertebrae 
Tuggle et al.
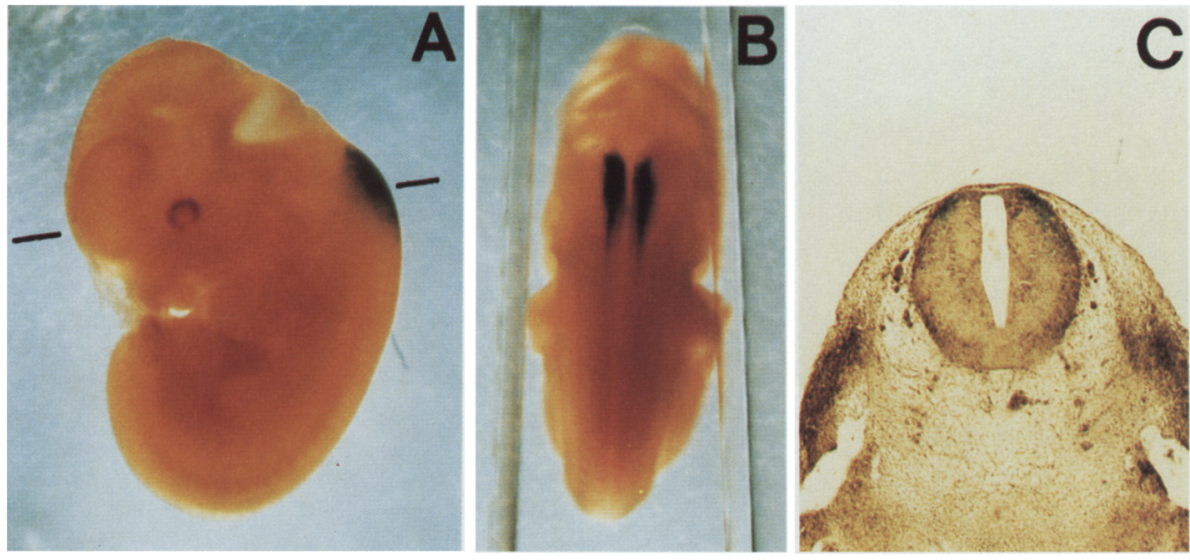

Figure 3. Region-specific expression of Hox-5.1/1.3/lacZ hybrid gene in the upper cervical spinal cord of transgenic mice. $(A)$ Wholemount lateral view of day 12.5 embryo shows $\beta$-galactosidase expression exclusively in the upper cervical region of the spinal cord. $(B)$ Dorsal view of the embryo in $A$ showing two columns of expressing cells in the spinal cord. $(C)$ Histological cross section of embryo in $A$ shows $\beta$-galactosidase expression is limited to the dorsolateral cells of the spinal cord. (Magnification, $35 \times$.)

(Featherstone et al. 1988). (The reasons for this difference will be discussed below.) Of the five expressors, three also showed expression in the metanephros (Fig. 4, panel 12.5), whereas two showed expression in the floorplate cells of the upper cervical CNS (data not shown). Expression in cells destined to give rise to kidney tissue is intriguing, since Hox-5.1 RNA has been found in the adult mouse kidney (Featherstone et al. 1988). However, both the lower frequency of this expression in transgenic embryos and the fact that Hox-1.3 RNA has also been observed in the newborn and adult mouse kidney (Odenwald et al. 1987; Zakany et al. 1988) makes it unclear whether metanephros expression is attributable to Hox-5.1 or Hox-1.3 sequences.

Expression of 5.1/1.3/lacZ is controlled at the transcriptional level by an enhancer element

It is likely that regulatory elements on the Hox-5.1 frag- ment control lacZ transcription from the heterologous Hox-1.3 promoter. Alternatively, Hox-5.1 promoter element|s/ could be involved in transcription of $l a c Z$ in the upper cervical CNS. To distinguish between these possibilities, the Hox-5.1 fragment was reversed in orientation. Of six independent embryos carrying this construct (5.1flip/1.3/lacZ in Fig. 1), three were found to express the transgene in the same pattern as seen with the previous construct (data not shown). This indicates that transcription of lacZ occurs from the Hox-1.3 proximal promoter and that regulatory elements on the Hox-5.1 fragment act independent of orientation. Because the Hox-1.3 promoter can be instructed by either the Hox-1.3 enhancer or the Hox-5.1 enhancer to become active in two different rostrocaudal regions of the CNS (Figs. 2 and 3), it is likely that the region specificity observed with Hox-5.1/1.3/lacZ gene fusions is encoded by the Hox-5.1 enhancer rather than by the Hox-1.3 promoter. On the other hand, it is not clear whether the
Figure 4. Expression of the 5.1/1.3/lacZ fusion gene is limited to embryonic day 10.5 to day 14.5 . $\beta$-Galactosidase expression in the upper cervical region begins on day 10.5 of gestation, increases to maximal levels on day 12.5 and 13.5 , decreases on day 14.5 , and is undetectable by day 15.5. The age of the individual embryos is indicated.

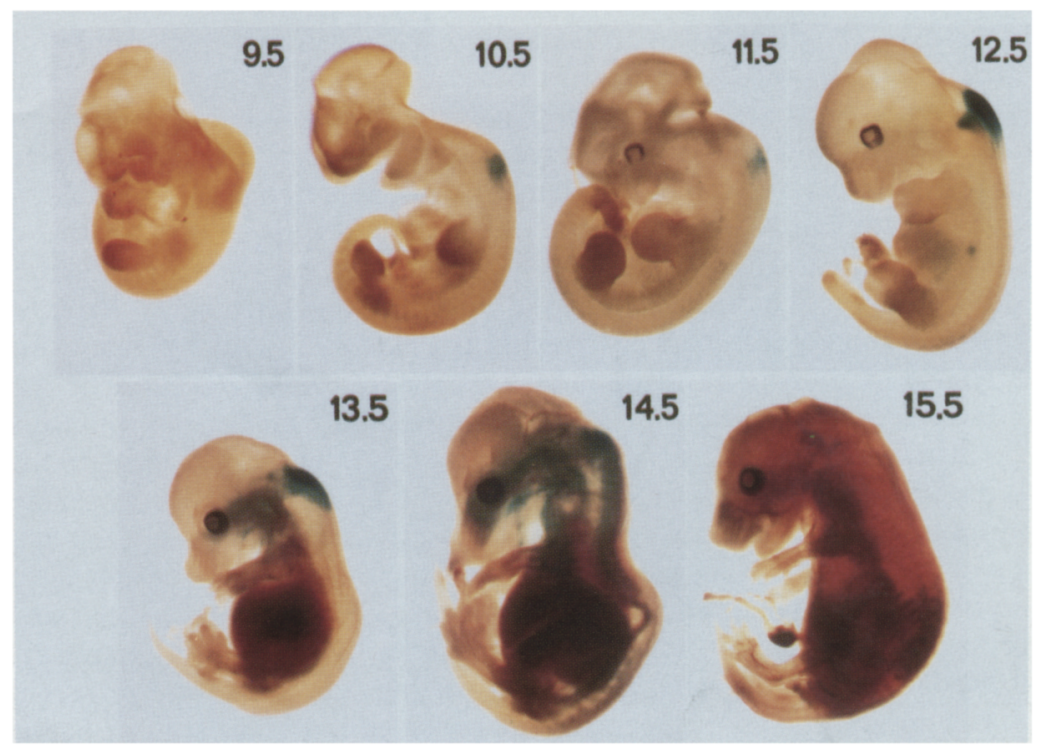


tissue specificity observed is encoded solely by the Hox-5.1 enhancer or may result from interactions between the Hox-5.1 enhancer and the Hox-1.3 promoter. Gene fusions between the Hox-5.1 enhancer and the hsp promoter would help to answer this question.

Activity of the 5.1/1.3/lacZ transgene is temporally controlled with expression detectable from embryonic day 10.5 to day 14.5

The Hox-1.3/lacZ gene has been shown to be temporally regulated during gestation, such that expression of $\beta$-galactosidase begins on day 11.5 , increases to maximal levels on day 12.5, persists on day 13.5, and is undetectable by day 14.5 (Zakany et al. 1988). To discover whether a similar temporal regulation is occurring with the Hox-5.1/1.3/lacZ gene, four transgenic lines were established and three lines showed expression of $\beta$-galactosidase in the upper cervical CNS of day 12.5 embryos. Expression of $\beta$-galactosidase during development for these lines was then investigated. Analysis of transgenic embryos at each day of gestation from day 9.5 to 15.5 indicates a temporal expression pattern similar (if somewhat more extensive) to that seen for the Hox-1.3/lacZ gene (Fig. 4). Expression is first observed in day $10.5 \mathrm{em}$ bryos, continues through to day 14.5 embryos, with maximal expression on day 12.5 and 13.5. Expression is undetectable by day 15.5 . This result is consistent with the finding that maximal expression of Hox-5.1 RNA was found at the earliest day of gestation examined, day 11 , and decreased to low levels by day 15 (Featherstone et al. 1988). $\beta$-Galactosidase activity outside the upper cervical spinal cord in day 13.5 and older embryos is attributable to endogenous enzyme activity, because this activity is reproducibly observed in both transgenic and nontransgenic embryos.

\section{Discussion}

Region-specific enhancers in the developmental regulation of mammalian Hox genes

Region-specific expression is one prerequisite of genes controlling pattern formation during development. All mammalian homeo box genes investigated thus far show spatially restricted expression in the embryonic central nervous system and often in the prevertebrae (Holland and Hogan 1988). How are these region-specific patterns generated? Our results support a simple regulatory model that would place region-specific enhancer elements near homeo box genes to direct their expression to discrete body regions. The Hox-1.3 and Hox-5.1 regulatory regions identified here clearly direct transgene activity to discrete rostrocaudal domains of the developing mouse CNS and have properties characteristic of transcriptional enhancers: they behave as cis-acting elements to regulate gene expression in a positive manner, they act in an orientation-independent fashion, and they confer specificity onto unrelated promoters. We propose that a likely function of these enhancer elements is to activate transcription from the Hox-1.3 and Hox-5.1 proximal promoters within the specific CNS domains that have been defined hare. Further analysis of the elements controlling the region-specific expression of other homeo box genes (Zakany et al. 1989) will be necessary to assess the generality of this model, but it is encouraging that our analysis has identified region-specific enhancers in the first two mammalian homeo box genes investigated. Whereas many mammalian tissue-specific enhancers have been identified and characterized (Maniatis et al. 1987; Atchison 1988), the mammalian enhancers reported here are the first to show region-specific activity. Tissue-specific control of transcription is often mediated by enhancers, which are believed to be composed of several smaller units or modules (Schaffner et al. 1988; Dynan 1989) whose effects are then combined and interpreted by the cell to produce specificity of expression. Thus, it will be of interest to dissect the enhancers defined here that have the ability to interpret positional information, as well as tissue-specific activity, into simpler components for comparative analysis. Deletion mapping and a comparison of the Hox-1.3 and Hox-5.1 enhancer regions will indicate DNA sequences important for temporal and tissue-specific CNS expression, and will also uncover sequences mediating region-specific expression within the CNS. Because the two enhancer regions identified here have been completely sequenced (Hox-1.3-Zakany et al. 1988; Hox-5.1 - L. Cianetti and C. Peschle, unpubl.), we compared their primary structure to determine whether regions of similar sequence exist that could contribute to common or similar characteristics of Hox-1.3 and Hox-5.1 expression. Using the sequence analysis program of the GCG group (University of Wisconsin), the most similar region was $\mathrm{TG}^{\mathrm{G}}{ }_{\mathrm{T}}{ }_{\mathrm{G}} \mathrm{TGCTGCTGT}^{\mathrm{G}} \mathrm{C}^{-}$ GGCA (15 of 18 in common, superscript nucleotides are from murine $\operatorname{Hox}-1.3$, beginning at 222 nucleotides $3^{\prime}$ to the BgIII site; subscript nucleotides are from human Hox-5.1, beginning at 923 nucleotides $3^{\prime}$ to the distal HincII site). This sequence similarity may be significant, as it was only found in the Hox-1.3 and Hox-5.1 enhancer regions, and not elsewhere in the Genbank and EMBL sequence data banks. Until additional mapping of the two regions is performed, however, the significance of this similarity is unclear.

Why are Hox-1.3/lacZ and Hox-5.1/lacZ transgenes expressed in only a subset of the endogenous Hox-1.3 or Hox-5.1 expression sites?

The CNS domains identified in transgenic mice by the Hox-1.3 and Hox-5.1 enhancers both represent specific subsets of the CNS regions expressing the endogenous Hox-1.3 and Hox-5.1 transcripts. We have shown that expression in the brachial spinal cord observed with Hox-1.3/lacZ transgenic embryos can be replicated when the mouse hsp 68 promoter and $5^{\prime}$-untranslated mRNA sequences replace the Hox -1.3 promoter and $5^{\prime}$ untranslated sequences. In addition, the Hox-1.3 promoter can be redirected to express $\beta$-galactosidase in the upper cervical spinal cord by regulatory elements near 
Hox-5.1. These results argue strongly against the possibility of cloning artifacts and the role of translational control in generating the regional expression patterns observed. Our data are most consistent with the possibility that the $\beta$-galactosidase patterns observed may specifically reflect the domains of CNS expression of the proximal promoters of $H o x-1.3$ and $H o x-5.1$, and that RNA expression detected in the other CNS regions by in situ studies may reflect the activity of the distal promoters. This possibility is supported by several other considerations. First, it has already been demonstrated that the multiple Hox-1.3 transcripts are not regulated in parallel in the CNS; the ratio of distal to proximal transcripts changes dramatically between midgestation and birth (Zakany et al. 1988; Garbern et al. 1989). Second, because all sequences on the proximal transcript are present on the distal transcript(s), in situ RNA analysis cannot distinguish between regions expressing the proximal transcript alone and regions expressing both the distal and proximal transcripts. However, in situ analysis of transgene expression in Hox-1.3/lacZ embryos shows that lacZ RNA is present only in the brachial region of the spinal cord (A. Perez-Castro, C.K. Tuggle and M.C. Nguyen-Huu, in prep.). This result indicates that the $\beta$-galactosidase pattern is controlled at the RNA level, and may reflect the pattern of the proximal transcript. Finally, and most importantly, we believe that the patterns of expression observed with the Hox-1.3/lacZ and Hox-5.1/lacZ transgenes are biologically consistent with the postulated homology between the Drosophila homeotic gene complexes and the different mammalian Hox gene complexes, as outlined below.

For homeo box genes in the Drosophila ANT-C/BX-C and the mammalian Hox complexes, a striking correlation exists between the anterior limits of expression of an individual gene and the order of that gene within the complex (Boncinelli et al. 1988; Gaunt et al. 1988; Graham et al. 1989; Duboule and Dolle 1989; Giampaolo et al. 1989, Wright et al. 1989). Genes at the $5^{\prime}$ end of the complexes are expressed more posteriorly, whereas genes at the $3^{\prime}$ end of the complexes are expressed more anteriorly. On the basis of conservation of both gene structures and expression patterns, it has been suggested that the Hox complexes and the ANT-C/BX-C complexes share a common ancestry and may be truly homologous chromosomal regions (for review, see Akam 1989; Wright et al. 1989|. Thus, we might expect an individual Hox gene to exhibit an anterior-posterior domain of expression similar to that of the Drosophila homeotic gene to which it is most similar in structure and position along the complex. For Hox-1.3 this is Sex combs reduced (Scr), while for Hox-5.1 this is Deformed (Dfd) (Graham et al. 1989; Duboule and Dolle 1989). Scr is expressed in a narrow region, including part of the posterior head and anterior thoracic region (Kuroiwa et al. 1985; Martinez-Arias et al. 1987). Interestingly, the $\beta$ galactosidase expression pattern in transgenic mouse embryos delineated by the Hox-1.3 enhancer spans the border between the lower cervical and anterior thoracic
CNS regions. $D f d$, the $3^{\prime}$ neighbor to $S c r$ in the ANT-C complex, is expressed in the posterior head, just anterior to the region expressing Scr (Martinez-Arias et al. 1987; Chadwick and McGinnis 1987). Similarly, the Hox-5.1/ $1 a c Z$ expression pattern is found entirely within the upper cervical CNS region, just anterior to the region expressing Hox-1.3/lacZ. Thus the adjacent expression in the murine CNS of the Hox-5.1/lacZ and Hox-1.3/ lacZ fusion genes is strikingly reminiscent of the adjacent expression in the Drosophila embryo of two neighboring homeotic genes, $D f d$ and Scr.

Whereas $D f d$ and $S c r$ are neighboring genes in the ANT-C complex, Hox-1.3 and Hox-5.1 are on two different complexes in the mouse. However, Hox-5.1 is the homolog of Hox-1.4, the 3 ' neighbor to Hox-1.3 (Duboule and Dolle 1989; Graham et al. 1989). Therefore, it is interesting to note that the CNS region expressing the Hox-5.1/lacZ transgene is identical to the CNS region expressing endogenous Hox-1.4 RNA (Toth et al. 1987). Moreover, it may not be coincidental that the CNS region expressing the Hox-1.4 RNA and Hox-5.1/lacZ transgenes is directly anterior to the CNS region expressing the Hox-1.3/lacZ transgene, considering that $3^{\prime}$ Hox genes are expressed more anteriorly than $5^{\prime}$ Hox genes.

\section{Specification of regional domains along the} rostrocaudal axis of the mammalian CNS

The mouse is thought to be a segmented animal, primarily because of the obvious metamerism in the somites and the subsequent vertebral column (Holland and Hogan 1988). There was little data to support similar ideas about segmentation in the central nervous system, although transient periodic swellings, called neuromeres (Lumsden and Keynes 1989) had been observed in the neuroepithelium in numerous vertebrates. Recently, however, axonal growth and cranial nerve development have been shown to follow the segmental pattern of neuromeres in the chick brain /Lumsden and Keynes 1989|. In addition, the zinc finger gene Krox-20 is expressed in two specific alternating neuromeres $\{\mathrm{r} 3$ and r5) of day 9.5 mouse embryos (Wilkinson et al. 1989), indicating that segmentation at the molecular level may exist in the hindbrain at this stage.

In this paper we show that region-specific enhancers associated with Hox genes can be used to define specific domains in the developing mammalian CNS. Whereas the CNS domains expressing Krox-20 comprise two alternating single neuromeres, the two CNS domains defined here span 6-7 metameres. We note that murine CNS domains expressing the different Xlhbox 1 gene products span 7-8 metameres (Oliver et al. 1988; Wright et al. 1989), and we suggest that the developing CNS may be subdivided into a series of 6-8 metamere long domains that are distinguished by having different combinations of homeo box proteins. The establishment of a series of such domains within the developing vertebrate CNS may be used to specify position along the rostrocaudal axis, in analogy to the patterning system 
found in Drosophila in which segment identity is defined by interaction of homeo box gene products with target genes. Using these established transgenic mouse lines, uncovering biochemical and functional differences between the cells in the upper cervical and the brachial CNS regions may now be possible. For example, fluorescence-activated cell sorting (FACS), in conjunction with a fluorescent $\beta$-galactosidase substrate (Nolan et al. 1988), can be used to purify specific "brachial" or "upper cervical" populations of spinal cord cells for further study.

\section{Methods}

\section{DNA cloning and manipulation}

The Bflip/1.3/lacZ gene was constructed by BgIII and XhoI digestion of $\mathrm{pHox}-1.3 /$ lacZ/SV40 (Zakany et al. 1988), filling in with Klenow enzyme, and religation to flip the orientation of the BgIII-XhoI region. This generated BgIII sites at both ends of the flipped region, so a partial BgIII and complete BamHI digest and subcloning into the BamHI site of pGEM2 was performed to allow isolation of large amounts of the 5800-bp fragment via digestion with Sall and BamHI for microinjection.

All further gene fusions were constructed within a new plasmid specifically designed to facilitate excision of large DNA fragments for microinjection, a step which may be problematic because unique restriction sites are required on both ends of the desired construct. NotI linkers were inserted at both the PvuII and EcoRV sites of pSP73 (Promega Biotec) to create pCKT15-11. This plasmid can be used to clone DNA constructs by the use of any of the 12 unique restriction sites between the NotI sites flanking the polylinker region. On successful cloning, the construct to be microinjected is excised by digestion with NotI, an enzyme recognizing an 8-base sequence and thus 16-fold less likely to cut within the desired DNA fragment as enzymes recognizing a 6-base sequence. For our purposes, we deleted the XhoI site on pCKT15-11 to create pCKT17-2, which was used to clone all further injected DNAs.

$\mathrm{B} / \mathrm{hsp} 68 / \mathrm{lacZ}$ was constructed by cloning the BgIII-XhoI (filled-in) 604-bp fragment from Hox-1.3 into pCKT 17-2 at the SmaI site to create $\mathrm{p} B g l X h o$. The 4200 -bp BamHI fragment (containing the $h s p 68$ promoter fused to the $l a c Z$ gene and SV40 sequences to provide intron/exon and polyA signals) from phspPTlacZpA (provided by J. Rossant) was then cloned into $\mathrm{p} B g I X$ ho at the BamHI site to create $\mathrm{pB} / \mathrm{hsp} 68 / \mathrm{lacZ}$.

The 7300-bp AccI-HindIII Hox-1.3/lacZ gene fusion (Zakany et al. 1988) was ligated into pCKT17-2 at the SalI, HindIII sites to generate pCKT32-47. A 2800-bp HincII human Hox-5.1 genomic fragment was isolated from a recombinant $\lambda$ phage and ligated to pCKT32-47 digested with SalI, XhoI and filled in with Klenow. Both orientations of the Hox-5.1 fragment relative to the 1.3/lacZ fusion were identified and named p5.1/1.3/lacZ and p5.1flip/1.3/lacZ.

Mouse strains, breeding, and production and analysis of transgenic mice

Mice were obtained from Jackson Labs except where noted. Fertilized eggs for microinjection were obtained from matings between superovulated C57BL6/DBA prepubescent females and C57BL6/DBA adult males. Pseudopregnant females for embryo transfer were produced by matings between C57BL6/DBA adult females and vasectomized CD-1 males (Charles River). Microinjection and oviduct transfer of injected embryos was per- formed as described (Hogan et al. 1986). Resulting pregnant females were either sacrificed at day 12.5 of gestation for $\mathrm{F}_{0}$ embryo analysis or allowed to bring fetuses to term for generation of transgenic lines. DNA isolated from placentas of embryos or the tails of live mice was used to ascertain transgenicity. Embryos were analyzed for $1 a c Z$ activity as described previously (Zakany et al. 1988), except that $0.25 \%$ glutaraldehyde in phosphate buffered saline was used to fix whole embryos prior to $l a c Z$ staining. The temporal pattern of expression of the $5.1 / 1.3 / 1 a c Z$ transgene was analyzed by breeding founder males with CD-1 females (Charles River). The day on which vaginal plugs were observed was designated day 0.5 of gestation. Pregnant females were then sacrificed on specified days of gestation and embryos were analyzed as above.

\section{Acknowledgments}

We thank Cindy Fabricus-Segal for technical advice on paraffin sectioning, Robert Deans and John Pintar for critical reading of the manuscript, and Janet Rossant for providing the $h s p 68$ plasmid vector. This work was supported by a National Cancer Institute postdoctoral training grant CA-09503-04 to C.K.T., a National Institutes of Health grant HD-22416 to M.C.N.-H. and grant Y-19650/88 from the Hungarian Ministry of Industry to J.Z.

\section{References}

Akam, M. 1989. Hox and HOM: Homologous gene clusters in insects and vertebrates. Cell 57: 347-349.

Atchison, M.L. 1988. Enhancers: Mechanisms of action and cell specificity. Annu. Rev. Cell Biol. 4: 127-153.

Balling, R., G. Mutter, P. Gruss, and M. Kessel. 1989. Craniofacial abnormalities induced by ectopic expression of the homeobox gene Hox 1.1 in transgenic mice. Cell 58: 337-347.

Boncinelli, E., R. Somma, D. Acampora, M. Pannese, M. D'Esposito, A. Faiella, and A. Simeone. 1988. Organization of human homeobox genes. Hum. Reprod. 3: 880-886.

Carrasco, A.E., W. McGinnis, W.J. Gehring, and E.M. DeRobertis. 1984. Cloning of an $X$. laevis gene expressed during early embryogenesis coding for a peptide region homologous to Drosophila homeotic genes. Cell 37: 409-414.

Chadwick, R. and W. McGinnis. 1987. Temporal and spatial distribution of transcripts from the Deformed gene of Drosophila. EMBO I. 6: 779-789.

Dony, C. and P. Gruss. 1987. Specific expression of the Hox 1.3 homeo box gene in murine embryonic structures originating from or induced by the mesoderm. EMBO J. 6: 2965-2975.

Duboule, D. and P. Dolle. 1989. The structural and functional organization of the murine HOX family resembles that of Drosophila homeotic genes. EMBO I. 8: 1497-1505.

Dynan, W.S. 1989. Modularity in promoters and enhancers. Cell 58: 1-4.

Fainsod, A., L.D. Bogarad, T. Ruusala, M. Lubin, D.M. Crothers, and F.H. Ruddle. 1986. The homeodomain of a murine protein binds $5^{\prime}$ to its own homeobox. Proc. Natl. Acad. Sci. 83: $9532-9536$.

Featherstone, M.S., A. Baron, S.J. Gaunt, M.-G. Mattei, and D. Duboule. 1988. Hox 5.1 defines a homeobox;containing gene locus on mouse chromosome 2. Proc. Natl. Acad. Sci. 85: 4760-4764.

Fibi, M., B. Zink, M. Kessel, A.M. Colberg-Poley, S. Labeit, H. Lehrach, and P. Gruss. 1988. Coding sequence and expression of the homeobox gene Hox 1.3 Development 102: 349359. 
Fienberg, A.A., M.F. Utset, L. Bogarad, C.P. Hart, A. Awgulewitsch, A. Ferguson-Smith, A. Fainsod, M. Rabin, and F.H. Ruddle. 1987. Homebox genes in murine development. Curr. Top. Dev. Biol. 23: 223-256.

Garbern, J., W. Odenwald, E. Tournier-Lasserve, and R.A. Lazzarini. 1989. Analysis of transcription of the murine homeobox gene Hox 1.3. In Cell to cell signals in mammalian development., NATO ASI Series (ed. S. deLaat, J.G. Bluemink, and C.L. Mummery) Springer, Berlin (in press).

Gaunt, S.J., P.T. Sharpe, and D. Duboule. 1988. Spatially restricted domains of homeo-gene transcripts in mouse embryos: Relation to a body plan. Development Suppl. 104: $169-179$.

Gehring, W.J. 1987. Homeobox genes in the study of development. Science 236: 1245-1252.

Giampaolo, A., D. Acampora, V. Zappavigna, M. Pannese, M. D'Esposito, A. Care, A. Faiella, A. Stornaiuolo, G. Russo, A. Simeone, E. Boncinelli, and C. Peschle. 1989. Differential expression of human HOX-2 genes along the anterior-posterior axis in embryonic central nervous system. Differentiation 40: 191-197.

Goto, T., P. MacDonald, and T. Maniatis. 1989. Early and late periodic patterns of even-skipped expression are controlled by distinct regulatory elements that respond to different spatial cues. Cell 57: 413-422.

Graham, A., N. Papalopulu, and R. Krumlauf. 1989. The murine and Drosophila homeobox gene complexes have common features of organization and expression. Cell 57: $367-378$.

Harding, K., T. Hoey, R. Warrior, and M. Levine. 1989. Autoregulatory and gap gene response elements of the evenskipped promoter of Drosophila. EMBO I. 8: 1205-1212.

Hiromi, Y. and W.J. Gehring. 1987. Regulation and function of the Drosophila segmentation gene fushi tarazu. Cell 50: 963-974.

Hogan, B.L.M., F. Costantini, and E. Lacy. 1986. Manipulating the mouse embryo: A laboratory manual. Cold Spring Harbor Press, Cold Spring Harbor, New York.

Holland, P.W.H. and B.L.M. Hogan. 1988. Expression of homeo box genes during mouse development: A review. Genes Dev. 2: 773-782.

Jaynes, J.B. and P.H. O'Farrell. 1988. Activation and repression of transcription by homeodomain-containing proteins that bind a common site. Nature 336: 744-749.

Kothary, R., S. Clapoff, A. Brown, R. Campbell, A. Peterson, and J. Rossant. 1988. A transgene containing lacZ inserted into the dystonia locus is expressed in neural tube. Nature 335: 435-437.

Kuroiwa, A., U. Kloter, P. Baumgartner and W.J. Gehring. 1985. Cloning of the homeotic Sex combs reduced gene in Drosophila and in situ localization of its transcripts. EMBO $J$. 4: 3757-3764.

Lumsden, A. and R. Keynes. 1989. Segmental patterns of neuronal development in the chick hindbrain. Nature 337: 424-428.

Mangalam, H.J., V.R. Albert, H.A. Ingraham, M. Kapiloff, L. Wilson, C. Nelson, H. Elshotz and M.G. Rosenfeld. 1989. A pituitary POU domain protein, Pit-1, activates both growth hormone and prolactin promoters transcriptionally. Genes Dev. 3: 946-958.

Maniatis, T., S. Goodbourn, and J.A. Fischer. 1987. Regulation of inducible and tissue-specific gene expression. Science 236: $1237-1245$.

Martinez-Arias, A., P.W. Ingham, M. Scott, and M.E. Akam. 1987. The spatial and temporal deploymnet of $D f d$ and $S c r$ transcripts throughout development of Drosophila. Devel- opment 100: 673-683.

Mavilio, F., A. Simeone, A. Giampaolo, A. Faiella, V. Zappavigna, D. Acampora, G. Poiana, G. Russo, C. Peschle, and E. Boncinelli. 1986. Differential and stage-related expression in embryonic tissues of a new human homeobox gene. Nature 324: 664-668.

McGinnis, W., M.S. Levine, E. Hafen, A. Kuroiwa, and W.J. Gehring. 1984a. A conserved DNA sequence in homeotic genes of the Drosophila Antennapedia and Bithorax complexes. Nature 308: 428-433.

McGinnis, W., R.L. Garber, J. Wirz, A. Kuroiwa, and W.J. Gehring. 1984b. A homologous protein coding sequence in Drosophila homeotic genes and its conservation in other metazoans. Cell 37: 403-408.

McGinnis, W., C.P. Hart, W.J. Gehring, and F.H. Ruddle. 1984c. Molecular cloning and chromosome mapping of a mouse DNA sequence homologous to homeotic genes of Drosophila. Cell 38: 675-680.

Murphy, S.P., J. Garbern, W.F. Odenwald, R.A. Lazzarini, and E. Linney. 1988. Differential expression of the homeo box gene Hox 1.3 in F9 embryonal carcinoma cells. Proc. Natl. Acad. Sci. 85: 5587-5591.

Nolan, G.P., S. Fiering, J.F. Nicholas, and L.A. Herzenberg. 1988. Fluorescence-activated cell analysis and sorting of viable mammalian cells based on $\beta-D$-galactosidase activity after transduction of Escherichia coli lacZ. Proc. Natl. Acad. Sci. 85: 2603-2607.

Odenwald, W.F., C.F.. Taylor, F.J. Palmer-Hill, V. Friedrich, Jr., M. Tani, and R.A. Lazzarini. 1987. Expression of a homeo domain protein in noncontact-inhibited cultured cells and postmitotic neurons. Genes Dev. 1: 482-496.

Odenwald, W.F., J. Garbern, H. Arnheiter, E. Tournier-Lasserve, and R.A. Lazzarini. 1989. The Hox-1.3 homeo box protein is a sequence-specific DNA-binding phosphoprotein. Genes Dev. 3: 158-172.

Oliver, G., C.V.E. Wright, J. Hardwicke, and E.M. De Robertis. 1988. Differential anterio-posterior expression of two proteins encoded by a homeobox gene in Xenopus and mouse embryos. EMBO \%. 7: 3199-3209.

Schaffner, G., S. Schirm, B. Mulleer-Baden, F. Weber and W. Schaffner. 1988. Redundancy of information in enhancers as a principle of mammalian transcription control. J. Mol. Biol. 201: 81-90.

Scott, M.P. and A.J. Weiner. 1984. Structural relationships among genes that control development: Sequence homology between the Antennapedia, Ultrabithorax and fushi tarazu loci of Drosophila. Proc. Natl. Acad. Sci. 81: 4115-4119.

Scott, M.P. and P.H. O'Farrell. 1986. Spatial programming of gene expression in early Drosophila embryogenesis. Annu. Rev. Cell Biol. 2: 49-80.

Toth, L.E., K.L. Slawin, J.E., Pintar, and M.C. Nguyen-Huu. 1987. Region-specific expression of mouse homeobox genes in the embryonic mesoderm and central nervous system. Proc. Natl. Acad. Sci. 84: 6790-6794.

Wilkinson, D.G., S. Bhatt, P. Chavrier, R. Bravo, and P. Charnay. 1989. Segment-specific expression of a zinc-finger gene in the developing nervous system of the mouse. Nature 337: 461-464.

Wolgemuth, D.J., R.R. Behringer, M.P. Mostoller, R.L. Brinster and R.D. Palmiter. 1989. Transgenic mice overexpressing the mouse homeobox-containing gene Hox 1.4 exhibit abnormal gut development. Nature 337: 464-467.

Wright, C.V.E., K.W.Y. Cho, G. Oliver, and E.M. De Robertis. 1989. Vertebrate homeodomain proteins: Families of regionspecific transcription factors. Trends Biochem. Sci. 14: 5256. 
Zakany, J., C.K. Tuggle, M. Patel, and M.C. Nguyen-Huu. 1988. Spatial regulation of homeobox gene fusions in the embryonic central nervous system of transgenic mice. Neuron 1: 679-691.

Zakany, J., C.K. Tuggle, and M.C. Nguyen-Huu. 1989. The use of lacZ fusions in the studies of mammalian development: Developmental regulation of mammalian homeobox genes in the CNS. I. Physiol. (Paris) (in press).

\section{Note added in proof}

To visualize directly the upper cervical and brachial CNS domains within the same mouse embryo, we crossed Hox-3.1 enhancer/lacZ transgenic mice with Hox-5.1 enhancer/lacZ transgenic mice. Progeny of this cross include embryos that contain and express both gene fusions (see cover picture). 


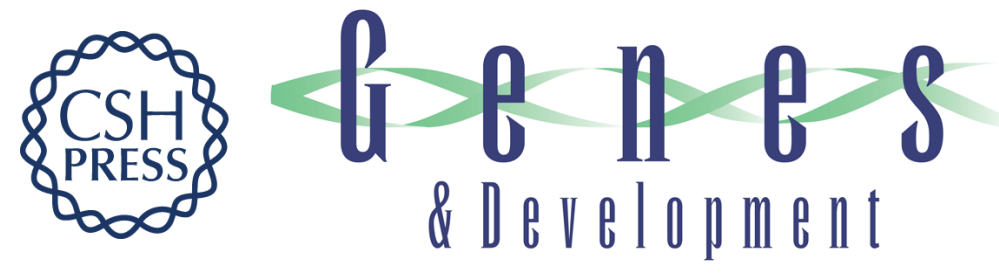

\section{Region-specific enhancers near two mammalian homeo box genes define adjacent rostrocaudal domains in the central nervous system.}

C K Tuggle, J Zakany, L Cianetti, et al.

Genes Dev. 1990, 4:

Access the most recent version at doi:10.1101/gad.4.2.180

References This article cites 45 articles, 14 of which can be accessed free at: http://genesdev.cshlp.org/content/4/2/180.full.html\#ref-list-1

License

Email Alerting

Service

Receive free email alerts when new articles cite this article - sign up in the box at the top right corner of the article or click here.

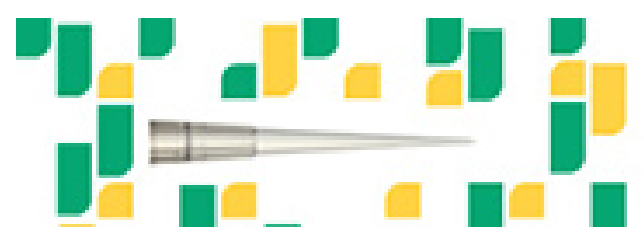

Focused on your science. 